\title{
Just Enough: Empowering Fixed-Line Telecommunications Consumers through a Quality of Service Information System
}

\author{
by
}

\author{
Patrick D. M. Barrow \\ ESRC Centre for Competition Policy and School of Computing \\ Sciences, University of East Anglia
}

\section{CCP Working Paper 07-2}

\begin{abstract}
Information, it is said, is power, and the proliferation of web-based information systems (IS) has made the potential for empowerment by information available to an increasingly large user population. The empowerment of consumers through quality of service information is a key component of modern UK economic and competition policy in order to both resolve certain information asymmetries between traders and consumers and facilitate switching, i.e. the ability of consumers to switch suppliers of goods and services. Using a case study approach, this paper concentrates not on the intricacies, physical design or specific information content of the IS itself but on the regulatory approach taken by the UK telecommunications regulator, Ofcom, to provide it. It considers how the mechanisms set up to provide and audit appropriate, comparable and reliable information actually favour the interests of the traders rather than the consumers. The result is that those people at whom such information is undoubtedly aimed (consumers) and who need it to make rational choices in the market are actually disempowered, particularly those vulnerable groups who may have special information requirements. It concludes that if consumers are to be properly empowered by information in such systems, the regulator must do more to better protect the consumer interest and provide them with information they actually need and not the information that the traders are willing to provide.
\end{abstract}

February 2007 
Keywords: Telecommunications, quality of service, information systems.

\section{Acknowledgements:}

I would like to thank Claire and Robert Milne for their thoughts on this issue and to Professor Catherine Waddams for her support and guidance. The support of the Economic and Social Research Council is also gratefully acknowledged.

Contact details:

Patrick D. M. Barrow, ESRC Centre for Competition Policy and School of Computing Sciences, University of East Anglia, Norwich, NR4 7TJ

p.barrow@uea.ac.uk 


\section{Introduction}

Empowerment of key groups has become an important component of UK government policy to help protect the interests of those who may not be able to protect their own. Consumers are said to be, at the time of writing (2006), one of the most empowered groups in modern society (Markillie 2005) as they become the focus for economic reforms as part of UK competition policy. The concept of consumer empowerment is central to the notion of competition and the notion of the empowered consumer is seen by bodies such as the Department of Trade and Industry (DTI) to be at the heart of an effective competition regime. Such empowerment, it is argued, is not only provided through competition but also requires an effective competition regime.

UK economic reforms have undergone considerable changes over the past 20 years in search of higher national productivity and prosperity. The traditional routes towards this end are thought to have reached the limits of their effectiveness (Porter and Ketels 2003), and more consumer-centric approaches have been proposed, moving regulation away from a bilateral model between regulator and regulated firm towards a more inclusive model where the interests of other stakeholder groups are taken into account, namely consumers. As will be shown later in the paper, despite the fact that regulators are there to protect the consumer, this 'inclusive' model may still give greater credence to interests which are likely to conflict with those of the consumer.

In 1997 the new Labour government announced a comprehensive review of regulation of the utilities, ultimately leading to reform via the Utilities Act 2000, Communications Act 2003, and the Water Act 2003. According to (Waddams Price, Harker et al. 2006), the "main thrust" of (DTI 1998) was that "the interests of shareholders had been given priority over those of consumers and, more specifically, that the benefits of competition were not being shared fairly by all consumers, in particular the vulnerable and disadvantaged".

A report on accountability within the regulatory state by the House of Lords raised concerns over the way that the consumer interest had been considered 
by regulators in general. Prior to the "setting up of independent consumer bodies, regulators were not necessarily able to take into account the interests of consumers, and to know clearly and consistently what those interests were". Also, "in balancing the interests of the regulated companies (and their investors) with the consumers, [they] might hear more of the company voice and have too great a regard for their interests" (House of Lords Select Committee 2004). It was proposed, therefore, that consumers should be given an effective and powerful voice within the regulatory system, and that the best way of realising this was through independent consumer bodies rather than regulators; this way, it was believed that the profile of consumers could be raised and their interests truly understood and represented in competition policy.

In what way can consumers be empowered through competition policy? It is suggested in (Hirschman 1970) that "consumers in a market...have two means of empowerment open to them when they are dissatisfied with the outcome of collective action. They can exit or they can voice". The provision of independent consumer bodies (e.g. energywatch, The Consumer Council for Water, Postwatch, etc.) provides the concept of 'voice' which empowers the consumer through representation of their interests to their respective regulators, although "questions have arisen over the way in which they interpret the consumer interest" (Waddams Price, Harker et al. 2006). Such bodies are "not chosen directly by consumer but instead are chosen by the regulator or a minister" (House of Lords Select Committee 2004) which raises the question in what sense directors and employees of such bodies actually represent consumer interests.

Since deregulation of the utilities and telecommunication markets (among others), consumers now have the choice of a variety of suppliers and 'exit' refers to consumers having the ability to switch from their incumbent supplier to suppliers who better meet their own particular requirements, e.g. lower cost, better customer service, 'greener' credentials, etc. However, in order to be able to 'exit' and switch to a 'better' supplier effectively, consumers require adequate and reliable information on which to make that choice. This paper 
considers the provision of the necessary information for consumers to be able to exit and switch.

The dissemination of information to consumers is central to both the notion of consumer empowerment and the government's philosophy of consumer protection. Existing information asymmetries between trader (i.e. those providing the telecommunications services) and consumer are now the focus of mainstream regulatory policy (Howells 2005) and steps are being taken to rectify them by ensuring that adequate information is made available by traders to consumers, notably (but not exclusively) through the internet. The volume and complexity of consumer information has led to the increasing use of internet-based information systems (IS) to help consumers more easily evaluate and understand their market options. For instance, uSwitch.com employs a rule-based IS to help consumers successfully find the best market deal for them given a number of conditions (e.g. postcode, payment preferences, etc.).

But what kinds of information do consumers require to 'exit'? In markets with largely homogeneous products and services (e.g. the utilities and telecommunications markets), consumers seeking to exit and switch are likely to be interested in a combination of price and quality of service (hereafter referred to as QoS) in order to differentiate between prospective traders and their goods or services. For example, a particular consumer might not mind paying a higher price for telecommunications services if the service provider can demonstrate evidence of superior response times for, say, fault rectification, etc. Whereas price information has, in theory, been more readily available to consumers (although it is not always in an easily comparable form), the provision of quality of service information has, in some cases, been incomplete and difficult for consumers to understand and compare. In the mobile and fixed-line telecommunications sectors for example, QoS reporting has been considered untenable because it has "not been meeting consumer requirements" (Oftel 2003b), although no further qualification has been provided by Oftel as to exactly how it had not been meeting them. 
Such information asymmetries mean that having access to information cannot, in itself, empower consumers unless steps are taken to verify its usefulness to them. Information which is unreliable, insufficient, inappropriate or obfuscated actually disempowers the consumer, because imperfect information will lead to their being unable to find their optimum provider, resulting in a welfare loss due to less than optimal trade taking place (i.e. the market will become less effective). Therefore, those who provide quality of service information systems with a view to empowering consumers should ensure that the information provided reflects the needs of the many consumers for whom the system is built. The next sections will consider the inadequacies of the existing system to provide such information and the regulatory approach taken by Ofcom to remedy the information asymmetries between trader (supplier) and consumer.

\section{Quality of Service Information in Fixed Line Telecommunications}

In 2003, the regulator for the telecommunications industry in the UK - the Office of Telecommunications (Oftel) - identified a problem with the supply of meaningful and comparable QoS information to help consumers differentiate between different mobile and fixed-line suppliers of telecommunications services. Previously such information had been made available by the traders themselves in a voluntary scheme, referred to as the Comparable Performance Indicators (CPIs) which supplied information on service provision, customer reported faults, service restoration, complaints handling and billing accuracy. In a survey requested by the voluntary industry body the Telecommunications Industry Forum (TIF) - to evaluate the usefulness and awareness of the information provided, it was ascertained that some sections of society were not benefiting from the CPI scheme, including those aged 55 and over, low income earners, the unemployed, and those in social classes A, B, D and E (Oftel 2000).

The effectiveness of the voluntary CPI scheme was believed by Oftel (which became part of Ofcom in December 2003) to be untenable, forcing them to rethink it in order to provide consumers with more reliable, objective and comparable information in a single web-based IS. Although in parts quite 
thorough and comparable, the information from the CPI scheme was, according to Oftel, not meeting consumer requirements (although exactly what those consumer requirements were was never clarified) and was deemed too technical, often incomplete, and poorly advertised and marketed. Within TIF, the body responsible for setting and measuring the QoS parameters, traders heavily outnumbered consumer representatives, who were restricted in the number who could attend. However, voting on issues, including setting and measuring of QoS parameters, required an $80 \%$ majority which actually gave the consumer-oriented minority something of a stronghold. This was, however, later changed to a straight majority, thus diminishing the impact of the consumer-oriented minority. Despite numerous requests from Oftel for changes which it felt would have made the schemes more beneficial to consumers, such changes proved difficult to achieve in practice.

Although the CPI scheme for mobile providers "continued to work to provide a constantly improving information product" (Ofcom 2004) through regular meetings of its members, the fixed-line scheme was considered in need of a thorough re-organisation, prompting a rethink of the whole future of quality of service reporting (both mobile and fixed-line). In its latter years, the fixed-line scheme's membership had declined sufficiently that many firms were now not actively participating in supplying information at all. The reticence of some traders to supply QoS information is perhaps understandable in that not only does it provide criteria against which they must be seen to succeed, but it may be difficult or expensive for them to measure and produce. Those traders that remained in the fixed-line scheme experienced a drop in the available funds for its continuation and there were no plans by them to 'improve' the existing information without further outside direction. Such a situation was considered not to be a suitable basis for providing consumers with the necessary information on which to make rational market choices.

It is clear from the experience of the fixed-line CPI scheme that the task of producing such information could not be left solely in the hands of the traders and that without a regulatory requirement "the ability to compare QoS information would be non-existent" (Energis 2004). This is backed by 
research by the Office of Fair Trading (OFT 1997) which suggests that in such cases traders might not provide the "optimum amount" of information for consumers, nor in the best way. Furthermore, a report by the National Audit Office (NAO 2003) argues that there is a "risk that suppliers' actions alone cannot be relied on to generate sufficient market awareness to meet the demands of consumers". Left to their own devices, and in the absence of both formal requirements to publish adequate and accurate information and adequate auditing procedures, some firms may not only not provide or advertise the availability of information to consumers but may also deliberately mislead them through:

- Obfuscation of their own information (e.g. retailers using price search engines as detailed in (Ellison and Fisher Ellison 2004));

- Substituting, in place of the required information, their own proxy information which it is convenient or inexpensive for them to provide;

- Mimicking the signals of other producers (e.g. by deliberately and fraudulently altering their own QoS information to 'compete' with rivals offering higher quality, despite the fact that their performance may actually be worse).

The importance of providing adequate QoS information is highlighted by the fact that where consumers are not able to access it, they may be forced to infer product or service quality from the pricing policies of the suppliers. Consumers could not, therefore, adequately differentiate between good and bad suppliers (in terms of service), which may lead, in a worst case scenario, to the driving out of high quality suppliers by their low quality counterparts. In addition, where suppliers did not have to provide such information, they may consider it justifiable to save money by cutting back on areas of customer service that were unmeasured (and thereby possibly unmanaged). So, for many reasons, suppliers cannot always be relied upon to provide the information that consumers need. If the providers themselves were not able or willing to provide it, the regulator, bound by a statutory duty to ensure that consumers had access to such information, would have to intervene to ensure 
a formal "regulatory backstop requirement" (Ofcom 2004) for suppliers to participate in such a scheme and provide the required information.

The case for Ofcom championing the rethinking of the provision of QoS information is strong. Under Article 22 of the European Union's Universal Service Directive (USD) (European Commission 2002), the National Regulatory Authority (in this case Ofcom) can ensure that "certain undertakings that provide publicly available electronic communications services (PECS) publish comparable, adequate, and up to date information for end-users on the quality of their services" (Ofcom 2004). In other words, Ofcom could, if it deemed necessary, force suppliers to participate and publish information whose content, form and manner is specified by them (Ofcom), thereby fulfilling its principal duties as set out in sections 3 and 4 of the 2003 Communication Act.

So, Ofcom has the power to require suppliers to participate in the scheme. However, participation of the suppliers far from guarantees the adequacy of any information they provide. As has been mentioned above, in order to ensure that information truly empowers consumers, steps must be taken by the regulator to understand their interests, not forgetting that "there is no simple and universal answer to what is in the interests of the consumer (nor indeed a single model of the consumer)" (Prosser 1999). For example some vulnerable members of society, to whom Ofcom have a statutory duty, have special needs that require having access to specific QoS information, and it is clear from (Oftel 2000) that in the case of those over 55, low-income earners, the unemployed, and those in social classes A, B, D and E, these needs were not adequately being met by the CPI scheme. The deaf and the elderly, for instance, require services such as "priority fault repair; relay services for text users; directory enquiries and provision of accessible contract and billing information" (DIEL 2003) in addition to information about the availability and quality of such services in their location. So, in order to fully inform and empower deaf and elderly users, along with other disabled and vulnerable groups, on their market choices, information on services critical to their specific needs would have to be provided. For example, the elderly or 
chronically sick who live in rural areas will want to know which suppliers provide priority repairs in their area.

Once appropriate QoS information is identified, steps must also be taken to validate it to ensure that it is both comparable and accurate, initially and over its lifetime. Consumers will only be empowered when they have access to complete, comparable, appropriate, and accurate information about their choices in the market, on parameters which reflect their needs. The next section looks at Ofcom's approach to regulation and considers its approach taken to understand the various consumer interests and to choose an appropriate regulatory option, information content, and validation mechanism for that information. The section thereafter will gauge to what extent the resulting QoS information system is likely to empower consumers of fixed-line telecommunication services.

\section{Ofcom's Approach To Regulation}

Because the decisions which Ofcom makes can impose significant costs on their stakeholders (particularly the traders), it considers its decisions carefully before adding to the burden of regulation. Ofcom has "a bias against intervention" (Ofcom 2005a) and even where regulation is justified, it will choose the least intrusive means of achieving given objectives.

Although regulation may often be required to help the market work more efficiently, there is also a danger that it can create unintended consequences which may be worse than the effects of the imperfect market it was designed to improve, so Ofcom will not regulate unless the intervention has been justified through a Regulatory Impact Assessment (hereafter referred to as an RIA) which is carried out prior to an intervention, and sometimes afterwards. The aim of an RIA is to provide a way to consider different regulatory options and then select the best option in order to further the interests of citizens and consumers. The 2003 Communications Act requires RIAs to be undertaken on 'important' proposals (a somewhat moveable feast!), although Ofcom regards them as sufficiently important that they are carried out in the great majority of their decisions anyway, stating "that they provide a mechanism for considering 
the impact of our work on the interests of the full range of the stakeholders, including different groups of citizens and consumers" (Ofcom 2005a). An RIA was carried out for the QoS project and is considered below.

To be able to serve the consumer interest, regulators need to be able to understand and articulate the consumers' position and interests. Ofcom embraces an evidence-based approach to regulation, involving considerable participation of stakeholder groups through consultation, and drawing upon existing research and the advice of its own Consumer Panel, which was established to advise it on the various consumer interests in the telecommunications market.

The Ofcom Consumer Panel differs from the statutory bodies established in the energy and the postal markets (DTI 2004) in that it is set up within the regulator itself as an independent body that can set its own agenda and speak out publicly on issues that it considers to be appropriate. Its aim is to represent the interests of people living in different parts of the UK, giving particular advice about matters relating to the interests of the statutory (vulnerable) consumer groups to which Ofcom has a special duty. The combination of the input of a specialist Consumer Panel combined with the consultative approach taken by Ofcom allows multiple specialist and stakeholder consumer viewpoints to be considered, providing it with the evidence on which to base its policy decisions. However, the introduction of a specialist consumer body separate from the regulator may reduce the extent to which the regulator feels obliged to represent the interests of consumers directly: the regulator may tend towards a position of balancing the pressures from the industry organisations and the consumer body. This could be particularly harmful to the interests of consumers if the consumer body is weak or does not consider the full range of consumer-related problems addressed by the regulator.

Unfortunately for the QoS project, the Panel wasn't set up until 2004, months after the initial policy direction had been proposed and the first consultation (explained below) had finished. In addition, although it commissions research 
across the whole market place, there are "a huge number of potential issues on which the Panel could carry out research and offer advice. As a consequence, the Panel could spend all its time on wide-ranging but superficial opinion-giving. In order to be effective, therefore, the Panel is selective" (OCP 2006a) and it limits itself to advising Ofcom on strategic matters only. One of the casualties of this decision is the issue of QoS which is deemed too 'low-level' to be a strategic issue, although one expert commentator stated that, in his opinion, effective regulation is in the detail, not just in high level strategic matters. Why the Panel has chosen not to comment on QoS is unclear, given that surveys show that QoS ranks ahead of price for consumers in some segments and second to price in others (Oftel 2003a).

It is telling that in their annual reports of both 2004-5 (OCP 2005) and 2005-6 (OCP 2006a), the Panel mentioned QoS only as an issue that they felt Ofcom should be pursuing themselves, i.e. without their input. They also stated their belief, consistent with (House of Lords Select Committee 2004), that Ofcom still had a real problem in actually defining the consumer interest; subsequently, the Panel spent considerable time in 2005 investigating how well Ofcom carried out the task of both understanding and taking on board the consumer interest (OCP 2006b) with a view to improving it.

The Consumer Panel cannot be a comprehensive sounding board on the whole range of consumer interest issues arising in its field of regulation without devoting more resources to those issues. Its budget was only $£ 655,000$ in 2004-5 and $£ 920,200$ in 2005-6 and approximately half of this goes on Panel members' fees and expenses, leaving relatively little for actual research on the range of issues they cover. So, if it wished to understand the consumer interests in QoS, Ofcom would need to find other avenues of evidence, through existing research or via its stakeholders through consultation documents.

If Ofcom is to require publicly available electronic communications services (PECS) to publish comparable QoS information, it must, under Article 22 of the Universal Service Directive (European Commission 2002), first take into 
account the views of interested parties, and although consultation can be a slow process - normally taking ten weeks for responses - it is used to ensure that a broad range of stakeholder groups can offer considered responses to proposed policies. Such responses are, according to Oftel "carefully and open-mindedly analysed, and the results made widely available, with an account of views expressed, and the reasons for decisions finally taken" (Oftel 2003b). All consultations and stakeholder responses - including those from members of the public and Ofcom - are published on Ofcom's web site unless the respondent wishes otherwise on the grounds of privacy. If a consultation is particularly complex, there will be a shortened, simpler version to make it accessible to members of the public.

A consultation document 'Reporting the Quality of Service Information to Consumers' (Oftel 2003b) was produced in November 2003 on four possible regulatory options for acquiring and publishing QoS information for telecommunications services. The aim of this particular intervention, according to the RIA, was to help deliver one of Oftel's four core high level objectives: that of the well-informed consumer, notably those "domestic and business consumers" who are considering switching. Despite explicit recognition by Ofcom that the consumer interest was not being met under the $\mathrm{CPI}$ scheme, nowhere in the RIA or any of their subsequent consultations or reports is it mentioned what this consumer interest was (and continues to be), nor how it could be served by an intervention aimed at so general a consumer profile (i.e. residential and business consumers). Although Ofcom had established an overall consumer need for complete, accurate and comparable QoS information, the consultation document did not ask about the provision of comparable information in relation to those services necessary to specific groups of consumers, despite:

1. Evidence in (Oftel 2000) detailing particular consumer groups who did not find the CPI scheme useful;

2. Evidence from the National Audit Office (NAO) showing that the telecommunications market is "very segmented (that is, there are wide variations in consumers' behaviour across age, location and social 
class) and that consumers in each segment have different needs". The NAO also stated (NAO 2003) that Oftel and Ofcom should use its own research into the needs and motivations underlying consumers' behaviour to sub-divide residential consumer profiles in order to target the information it provides to consumers, taking into account such factors as geographical location, age and ethnic group;

3. Ofcom's having a duty towards so-called vulnerable groups (i.e. those in rural areas, the elderly, disabled or those on low incomes).

There may be a number of reasons why the needs of specific consumer groups had not been considered. Firstly, Ofcom is guided by a principle of proportionality in that it has a duty to ensure that any interventionist policy is fair and proportionate for all types of trader and service provider. This means that any regulatory action taken should be proportional to the perceived impact of the decision on them. If consideration were given to the information needs of different consumer groups, there would likely be an increased burden placed on the traders who may then have to supply a far greater range of information than under the previous CPI scheme which only provided information on the general areas of contact between trader and consumer. Any increased costs incurred by the suppliers in collecting such information may be passed on to the consumers so that whatever saving they may have enjoyed through switching may be nullified by higher overall charges. Secondly, any requirement to provide information specific to particular consumer groups, e.g. the disabled, "would have to pass a test of proportionality and consumer detriment, would require further research, and may require its own public consultation" (Ofcom 2004), indicating the lack of appropriate research on which Ofcom could draw. Such a proportionality test was not carried out during the consultations relating to the QoS issue. Thirdly, like the Consumer Panel, Ofcom is constrained by its budgets and must ensure proportionality in its distribution of resources with the many other competing areas within its remit. Given that the Consumer Panel does not consider the QoS issue within its strategic remit, Ofcom would either have to draw upon existing research or conduct or commission it themselves. Fourthly, there has not, until recently, been a formal stipulation to consider the 
interests of particular vulnerable groups in RIAs. At the time the RIA was produced (2003), the requirements for carrying them out were less stringent than would be the case today. Since 2003 a range of more consumer-specific laws have been introduced with which Ofcom will be forced to comply, relating to specific sections of society, including some vulnerable groups. For example, in order to comply with the Race Relations Act 2000, The Northern Ireland Act 1998, and the Disability Equality Scheme (GLA 2005), Ofcom will, in future, have to conduct an RIA to assess the relevance of proposed policies to those who are disabled and those who belong to one or more racial groups, although this does not extend to the need to guarantee provision of relevant QoS information to those groups. For policies affecting Northern Ireland, the impact on nine groups in society must be assessed (e.g. those of different sexes, religious beliefs, political opinions, etc.). Lastly, one of the reasons for consulting is to find out the thoughts of various stakeholders on the possible parameters that could be used in any future system. By starting at a general level, they could, through stakeholder responses, take into account the needs of various stakeholder groups and add in any parameters they saw fit.

However, before any consideration could be given to the needs of consumers and the choice of parameters, Ofcom's first task was to decide what policy option to apply in relation to reporting and publishing QoS metrics for both mobile and fixed-line suppliers (although only fixed-line will be discussed here). Four choices were offered to respondents in the first consultation. These choices were:

1. Abandon all schemes (no regulatory requirement);

2. Maintain the current CPI schemes;

3. Maintain a co-regulatory framework, but put in place minimal regulatory requirements. In other words, force many traders to provide information but continue to leave the management of the scheme to them;

4. Direct regulation. The regulator sets the reporting criteria and method and sets sanctions for non-compliance. 
Although there was some support for options 1,2 and 4, there was a majority of respondents in favour of option 3 for fixed-line providers, and this was the option duly chosen by Ofcom, although it gave no indication as to how these stakeholder responses actually influenced its final decision to choose option 3.

Option 1 would have left consumers with little or no comparable QoS information, which may or may not then be provided by the traders themselves and would almost certainly not be available in a single location (a so-called 'One Stop Shop'). Option 2 would have kept the status quo, providing no apparent advantage to the old CPI scheme which Ofcom deemed in need of replacement. Option 4, while forcing traders to participate in the scheme and minimising their influence on the parameters and format in which the information would be provided to consumers, would also be contrary to Ofcom's stated desire of more self-regulation and minimal regulatory intervention to achieve its goals. Instead it would be considered to be maximising the regulatory intervention needed to satisfy perceived consumer requirements because of the burden it would place on both Ofcom and the traders. According to (Oftel 2003b), option 4 would involve the need for greater levels of resourcing by them (Ofcom), including the need for a testing facility, independent auditor, and an independent publication provider. Option 3 would at least satisfy Ofcom's duties under the Communications Act by forcing all fixed-line service providers of a certain size to provide comparable, adequate and up to date information to consumers. Although Ofcom have the power under Article 22 of the USD (European Commission 2002) to specify the QoS parameters to be used should they need to, option 3 does not require Ofcom to specify them, only to provide a direction.

Phase two of the consultation took place in September 2004 (Ofcom 2004) and sought to identify the parameters for the new scheme. Sections 4 (9) and (10) of the Communications Act and Article 22 of the USD encourage compliance with the parameters, definitions and measurement methods used in the European Telecommunications Standards Institute (ETSI) 201769 standards (ETSI 2000), thus bringing them in line with many European National Regulatory Authorities. Ofcom subsequently recommended four 
ETSI parameters plus an additional two as a starting point on which respondents could comment. These measures were: supply time for initial completion, fault rate per access line, fault repair time, bill correctness complaints, complaint handling and number of consumer disconnections. Ofcom believed that these parameters would provide sufficiently comprehensive information to end-users in order to meet its objectives under the Communications Act, because they capture the main quality issues between end-users and their service providers (ordering services, fault repair, complaints handling and accurate billing).

The ETSI measures are aggregated across all classes of customers and although those explicitly bound by these standards do not have to provide statistics for different classes of consumer, they should, however, allow for performance to be analysed at a regional level; no less than level 2 of the Nomenclature of Territorial Units for Statistics. This means in effect that all ETSI parameters should allow, in the case of the UK, for QoS performance to be assessed at the county level in England and at the unitary authority level in Northern Ireland, Wales and Scotland. Consumers could, therefore, find information relating to quality of service issues within their own area, which may (or may not) differ substantially from a national average and which may be critical in their decision to switch to a given supplier whose local performance satisfied a consumer's requirement. In adopting these measures therefore, traders would have to provide a greater breakdown of information than under the CPI.

Despite their criticism of the effectiveness of the old CPI scheme, and their apparent support of the ETSI-based parameters, Ofcom's commitment to their ultimate use did not appear to be very strong. In response to industry respondents' comments about the similarity of the ETSI parameters to the old $\mathrm{CPI}$ parameters and their wish to continue using them, Ofcom considered that "the base set of information utilised previously by TIF (i.e. CPI) is a useful set of information and that the frequency and methods of publication are also sound approaches that could be adopted by the new co-regulatory group" (Ofcom 2005b). This may be because many industry respondents had felt 
that the ETSI parameters were inappropriate to contemporary UK telecommunications, because they only relate to direct services, thereby excluding indirect services and with it a significant percentage of UK telecommunication users. It is not surprising, then, that the new co-regulatory group charged with responsibility for deciding upon information content - now named Topcomm - chose to reject the use of the ETSI parameters and revert back to using the CPI measures in which they had invested so much time and effort.

There is also concern about the traders' interpretation as to how some parameters are to be measured. For fault repair, although consumer representatives in Topcomm stated their desire to see information on how long it took on average to repair reported faults, what traders will actually provide (as of 2006) is whether or not that trader stuck to its commitment to repair within a set number of hours or days. Such information is unlikely to meet the needs of various vulnerable groups who rely on having guaranteed telephone communications (e.g. the elderly or disabled) because it does not allow them to differentiate between firms who on average fix within, say, 3 hours and those who fix within 18 hours or even a promised 3 day period. Vulnerable groups such as the elderly - who statistically are less likely to have mobile phones - are thus more reliant on their fixed-line telephone for communication with relatives or emergency services. Therefore, information on the average time it takes a firm to fix a fault is more useful to such consumers than the percentage of faults that were fixed within a given time frame.

Currently, Topcomm consists of around thirty industry representatives and three consumer advocacy representatives, although these numbers are not fixed. The former number varies as firms merge, drop out or enter the market. Although Topcomm state that more consumer representatives are welcome to join, there is a problem getting suitable people/bodies to volunteer to take part. Although Ofcom provide input and direction into Topcomm, they do not assume responsibility for its daily functioning. Voting on issues (including choice and measurement of parameters) has moved from the previous $80 \%$ 
majority to a now overall majority providing an even greater stranglehold for the industry representatives who outnumber those who currently represent the interests of various consumer groups by ten to one. Although the consumer advocates may provide useful input into decision-making, the industry has essentially retained total control over the parameters used and how they are to be measured, despite previous concerns over their ability to supply relevant information to consumers and evidence that some vulnerable portions of society were not being served by the information previously produced.

The industry has also retained a high degree of control over the means by which the accuracy and comparability of the parameters are audited and the way in which parameters periodically evolve. In allowing traders to self-audit any information they provide, a question must be raised over the objectivity of a trader who finds errors in their own information, and whether they will report any such errors to Ofcom, who may, depending on the severity of the issue, issue a heavy financial penalty. It is also worth asking whether, in the knowledge of the absence of a detailed independent audit, traders will be prepared to let 'bad news' (QoS information that puts them in a bad light compared to competitors) into the marketplace. Furthermore, although an independent comparability auditor has been appointed to assess the extent to which the information is comparable across traders, the audit is done on a reactive basis. In other words, it relies on traders calling the auditor in response to perceived problems and so it is largely down to the integrity and honesty of individual traders whether problems are identified and remedied. There seems little incentive for the auditor to actually look for problems other than those that are identified by traders.

One of the original problems with the CPI scheme was the lack of awareness among consumers about its existence; $60 \%$ of consumers surveyed in (Oftel 2000) were unaware of the existence of fixed-line telecommunications QoS comparators. Although Topcomm is obliged to find ways of better advertising the replacement scheme, it remains to be seen how this will be achieved. Whereas Ofcom can force traders to provide information, it cannot force them to make it easy for consumers to find it. Traders are not obliged to advertise 
the scheme to their consumers on their own material, which would have been one of the more effective and obvious places to put it and which would have ensured that consumers would receive some indication of its existence whenever they received, for instance, a bill or statement.

The Fixed-Line website went live on $28^{\text {th }}$ July 2006 and its success or otherwise, as with all ISs, cannot be verified until it has been operational for some time. Ofcom carried out an initial evaluation in September 2006, 3 months after going live, although their approach both in terms of evaluands and mechanisms is uncertain at this point. They also intend to continue to reevaluate the parameters periodically with a view to providing increasingly more effective iterations of the system. However, unless the stranglehold of the traders is diminished within Topcomm, or Ofcom take a more consumeroriented approach to such interventions, there is little reason to believe that this system, or future iterations of it, will be any more useful to consumers than the flawed scheme it was designed to replace.

\section{Who will this system empower?}

This system has the potential to empower consumers and redress the existing information asymmetries between themselves and the traders. However, this case study demonstrates that consumers' empowerment is likely to remain limited, even where:

- Consumer empowerment through information is deemed of such high importance to competition in the UK fixed-line telecommunications market which has the weight of EU and UK competition policy behind it;

- Consumer bodies have been set up specifically to represent the consumer interests to the regulator, and;

- The regulators themselves have instigated the development of an information system to rectify existing asymmetries.

Despite various warnings about the dangers of leaving information provision in the hands of the traders, this, in effect, is what has happened and it is hard to see this proposed system as much of an improvement on its predecessor 
except that some comparable information is now guaranteed from many traders, who still have control over the choice of parameters used, and the way they are measured, presented and audited. Although the parameters chosen will provide some useful guidance to consumers on general QoS issues, there is no evidence that they will address the needs of the groups identified as being poorly served by the original CPI scheme, those deemed in most need of adequate QoS information, or those vulnerable groups to whom Ofcom has a special duty.

\section{Conclusion}

Ofcom have produced what they set out to produce - a system to provide comparable QoS information to domestic and business consumers. They have complied with their statutory duties and at the time of the intervention, they were under no obligation to look at how the policy might impact upon specific consumers or portions of society or to guarantee provision of information for those groups. However, for the consumers, this is not good enough and must raise questions about the remit and funding of both Ofcom and its Consumer Panel, which is likely to require intervention from a higher source (e.g. government or EU). Co-regulation, although deemed proportional and relatively unintrusive, works, in this instance, firmly in favour of the traders who can choose to supply information that is convenient to them rather than that which gives proven value to the consumer. Additionally, the principle of proportionality towards traders and service providers - by which Ofcom is guided - also does the consumers few favours, as does Ofcom's bias against intervention. Surely in cases where the consumer is not receiving the information it requires, a stronger intervention is necessary to ensure that it does.

Even if Ofcom had aimed this system at specific consumer groups and been able to identify their information needs, they were, under option 3, in no position to impose such requirements on the traders. Arguably, the only way that consumers could be truly empowered is through direct regulation (option 4) where traders would be forced to present given information, dictated by Ofcom, in predefined ways. However, the increased burden on both Ofcom 
and the traders of option 4, despite its popularity among some consumer advocates, may make it a potentially expensive solution for all parties.

Although Ofcom's ability to understand the needs of the consumer may improve with the adoption of the Consumer Panel's new audit toolkit (OCP 2006b), the largely hands-off and light touch approach to regulation taken by Ofcom appears driven more around the immediate detrimental impact such interventions might have on the traders than the benefits they might provide to consumers. There is little indication that even with a better future understanding of the consumers' interests, this will translate into more consumer-oriented future iterations of the QoS system because all decisions pertaining to it still have to pass through Topcomm. Overall, there is limited evidence that Ofcom has the power to be able to empower consumers through QoS information, and until it can consumers are likely to remain poorly informed about QoS issues in the fixed-line telecommunications market.

All this serves to prove that even with the full weight of UK and EU competition policy behind it, developing IS to provide consumers with relatively simple information is still a difficult and politically-charged task. 


\section{References}

DIEL (2003). Response to Oftel Consultation 'Reporting Quality of Service Information to Consumers'. Advisory Committee - Telecommunication for the Disabled and Elderly (DIEL).

DTI (1998). A Fair Deal for Consumers: Modernising the Framework for Utility Regulation, Green Paper. London, The Stationery Office.

DTI (2004). Consumer Representation in Regulated Industries.

Ellison, G. and Fisher Ellison, S. (2004). Search, Obfuscation, and Price Elasticities on the Internet, Massachusetts Institute of Technology \& National Bureau of Economic Research.

Energis (2004). Reporting Quality of Service Information on Consumers: Energis Response to Ofcom Consultation Document, Energis.

ETSI (2000). Speech Processing, Transmission \& Quality Aspects (STQ); QoS Parameter Definitions and Measurements; Part 1: Parameters for Voice Telephony Service Required Under the ONP Voice Telephony Directive 98/10/EC, European Telecommunication Standardisation Institute (ETSI), France.

European Commission (2002). On Universal Service and Users' Rights Relating to Electronic Communications Networks and Services (Universal Service Directive). Directive 2002/22/EC.

GLA (2005). The Greater London Authority's Disability Equality Scheme: Moving Towards Equality for Disabled and Deaf Londoners. London, Greater London Authority.

Hirschman, A. O. (1970). Exit, Voice and Loyalty. Responses to Decline in Firms, Organizations and States. Cambridge, MA., Harvard University Press.

Howells, G. (2005). "The Potential and Limits of Consumer Empowerment by Information." Journal of Law and Society 32 (3): 349-70.

House of Lords Select Committee on the Constitution (2004). The Regulatory State: Ensuring its Accountability, HL Paper 68 I., London: The Stationery Office.

Markillie, P. (2005). Crowned at Last. The Economist. April 2nd.

NAO (2003). The Office of Telecommunications: Helping Consumers Benefit from Competition in the Telecommunications Market, National Audit Office.

OCP (2005). Annual Report 2004-5, Ofcom Consumer Panel.

OCP (2006a). Annual Report 2005-2006, Ofcom Consumer Panel. 
OCP (2006b). Capturing The Consumer Interest: A Toolkit for Regulators and Government. London, Ofcom Consumer Panel.

Ofcom (2004). A Statement on providing quality of service information to consumers: A Consultation on quality of service parameters including a Notification and Draft Direction. London, Office of Communications.

Ofcom (2005a). Better Policy Making: Ofcom's Approach to Impact Assessment. London, Office of Communications.

Ofcom (2005b). A Statement on setting quality of service parameters: Notification of Direction. London, Office of Communications.

OFT (1997). Consumer Detriment Under Conditions of Perfect Information. London, Office of Fair Trading.

Oftel (2000). Awareness and Use of Comparable Performance Indicators for Fixed-Link Telecoms Suppliers, The Office of Telecommunications.

Oftel (2003a). Consumers Use of Fixed Telephony, Office of Telecommunications.

Oftel (2003b). Reporting Quality of Service Information to Consumers: A Consultation on the Regulatory Options for Acquiring and Publishing Quality of Service Measures for Telecommunication Services, Office of Telecommunications.

Porter, M. E. and Ketels, C. H. M. (2003). UK Competitiveness: Moving to the Next Stage. Institute of Strategy and Competitiveness, Harvard Business School.

Prosser, A. (1999). "Theorising Utility Regulation." Modern Law Review 62(2).

Waddams Price, C., Harker, M., et al. (2006). Regulation and Consumer Representation. International Handbook of Economic Regulation. M. Crew and D. Parker. Cheltenham, Edward Elgar. 